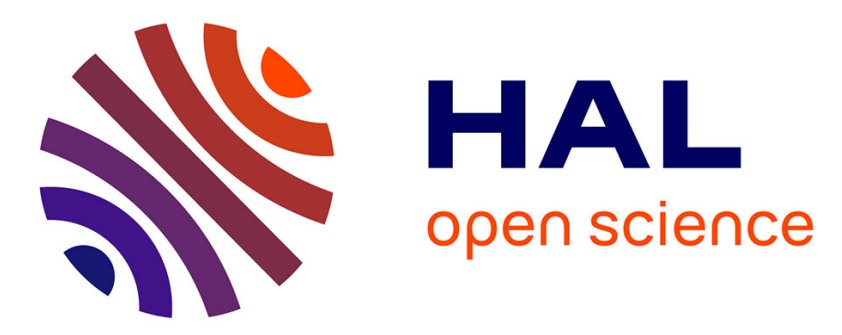

\title{
An experimental investigation on the boron trichloride hydrogen plasma reactions at medium and high pressure
}

\author{
M. Diana, C. Luponio, G. Russo
}

\section{To cite this version:}

M. Diana, C. Luponio, G. Russo. An experimental investigation on the boron trichloride hydrogen plasma reactions at medium and high pressure. Revue de Physique Appliquée, 1977, 12 (9), pp.12371242. 10.1051/rphysap:019770012090123700 . jpa-00244304

\section{HAL Id: jpa-00244304 https://hal.science/jpa-00244304}

Submitted on 1 Jan 1977

HAL is a multi-disciplinary open access archive for the deposit and dissemination of scientific research documents, whether they are published or not. The documents may come from teaching and research institutions in France or abroad, or from public or private research centers.
L'archive ouverte pluridisciplinaire HAL, est destinée au dépôt et à la diffusion de documents scientifiques de niveau recherche, publiés ou non, émanant des établissements d'enseignement et de recherche français ou étrangers, des laboratoires publics ou privés. 


\title{
AN EXPERIMENTAL INVESTIGATION ON THE BORON TRICHLORIDE HYDROGEN PLASMA REACTIONS AT MEDIUM AND HIGH PRESSURE (*)
}

\author{
M. DIANA, C. LUPONIO and G. RUSSO \\ Laboratorio Ricerche Combustione del C. N. R., Napoli \\ Istituto di Fisica. Facoltà di Ingegneria. Università di Napoli \\ Istituto di Chimica Industriale e Impianti Chimici. Università di Napoli, Italy \\ (Reçu le 30 décembre 1976, révisé le 6 juin 1977, accepté le 13 juin 1977)
}

\begin{abstract}
Résumé. - On expose les résultats d'une étude expérimentale des réactions de réduction du $\mathrm{BCl}_{3}$ avec hydrogène dans le plasma thermique d'un arc et dans le plasma hors d'équilibre d'une décharge glow. Dans la première étude le générateur de plasma agit avec un mélange hydrogène-argon $\left(\left(\mathrm{H}_{2}\right) /(\mathrm{Ar})=3\right)$, un débit de 40-90 $1(\mathrm{STP}) / \mathrm{min}$. et une puissance de 8-15 kW. Les observations ont été effectuées dans l'intervalle 3-20 du rapport moléculaire $\left(\mathrm{H}_{2}\right) /\left(\mathrm{BCl}_{3}\right)$. Dans la seconde expérience le procédé de réduction se produit à basse pression dans un tube à décharge à haute tension; la puissance est alors de l'ordre de $100 \mathrm{~W}$ et le débit de $2 \mathrm{l} / \mathrm{s}$. La réaction au plasma thermique a donné des conversions $\mathrm{du} \mathrm{BCl}_{3}$ en bore solide jusqu'à $70 \%$ en bon accord avec les prévisions thermodynamiques. Le produit se présente en forme d'une poudre d'une finesse très grande. Au contraire le bore obtenu avec un plasma hors d'équilibre est apparu sur les parois du tube de décharge aussi bien que sur les surfaces du cathode. L'étude spectroscopique dans le domaine visible et l'U. V. a toujours mis en évidence dans la décharge glow les émissions de $\mathrm{H}, \mathrm{B}, \mathrm{H}_{2}, \mathrm{BH}, \mathrm{BCl}$ et des espèces polyatomiques, les deux derniers étant absents dans la réaction due au plasma thermique. Les lignes de la branche $\mathrm{R}$ de la transition ${ }^{1} \Pi \rightarrow^{1} \Sigma \mathrm{du} \mathrm{BH}$ nous ont permis de mesurer la température rotationnelle de la flamme de réduction du procédé thermique.
\end{abstract}

\begin{abstract}
Results of experimental investigations on the endothermic reduction of $\mathbf{B C l}_{3}$ in a hydrogen thermal plasma and in a non-equilibrium hydrogen plasma discharge at medium pressure are presented. In the first experiment the apparatus was operated with a hydrogen-argon mixture $\left(\left(\mathrm{H}_{2}\right) /(\mathrm{Ar})=3\right)$ with a flow-rate of 40 to 901 (STP)/min. and a power input in the range 8 to $15 \mathrm{~kW}$. The $\left(\mathrm{H}_{2}\right) /\left(\mathrm{BCl}_{3}\right)$ molar ratio investigated was in the range 3 to 20 . In the second experiment the reduction process was carried out at lower power input and flow-rate in the glow of a high voltage discharge glass tube.

In the arc-plasma experiments conversion degrees of $\mathrm{BCl}_{3}$ to solid boron up to $70 \%$ were obtained in agreement with thermodynamic predictions. The boron was collected as an extremely fine powder $(0.05$ to $0.15 \mu \mathrm{m}$ diameter). In the glow discharge experiments, heterogeneous boron nucleation and growth was observed on both the discharge tube walls and cathode surfaces.

From the visible and near U. V. spectroscopic investigations, there was always evidence for the presence of $\mathrm{H}, \mathrm{B}, \mathrm{H}_{2}, \mathrm{BH}, \mathrm{BCl}$ and polyatomic species in the glow experiments, the last two being absent in the plasma process. R-branch lines of the $1 \Pi \rightarrow 1 \Sigma$ BH transition were used to obtain measurements of rotational temperatures in the high pressure reduction flame.
\end{abstract}

1. Introduction. - Boron trichloride - hydrogen endothermic reactions have been tested in recent years in order to obtain high purity boron or gaseous hydrogen-boron compounds. In particular, the boron reactivity with practically any kind of compound at high temperature increases the interest in developing reduction processes, since this avoids the use of growth surfaces to condense solid boron from the gaseous phase. Recently, following the development of plasmo-

(*) Communication presented at the Congrès National de Physique des Plasmas, 6-10 décembre 1976. chemical technology, similar processes have been attempted by Biggerstaff [1] using a plasma torch, by Markovskii [2] in a glow discharge at medium pressure and by Hamblyn et al. [3] in a radiofrequency plasma at atmospheric pressure.

In a previous paper [4] preliminary results obtained in the development of an arc-plasma process at atmospheric pressure were reported. The $\mathrm{BCl}_{3}$ reduction reactions, nucleation and growth of solid boron particles occurring at high temperature in the gaseous phase were described.

In the present paper results concerning more exten- 
sive investigations on this process are presented. The research has also been extended to a reduction process carried out in a non-equilibrium hydrogen plasma glow discharge at medium pressure.

2. Experimental apparatus. - Figure 1 shows the scheme of the equipment used in the arc-plasma experi-

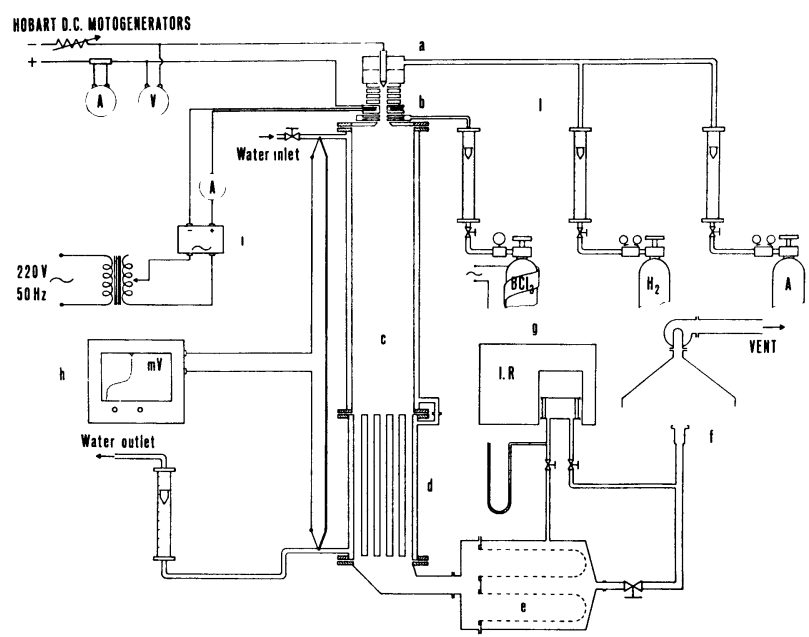

Fig. 1. - Layout of the arc-plasma experiment. (a) Arcplasma generator, wall stabilized type, cooled by high pressure water flow. The copper segments $(10 \mathrm{~mm}$ i.d., $6 \mathrm{~mm}$ thickness $)$ are electrically insulated by Teflon orings. The thoriated tungsten cathode is cone-shaped, $17 \mathrm{~mm}$ distant from the copper annular anode inlet (10 $\mathrm{mm}$ i.d., $12 \mathrm{~mm}$ length), which is wound to generate an axial d.c. magnetic field of about $350 \mathrm{G}$ intensity. (b) $\mathrm{BCl}_{3}$ feeding segment with two radially opposite bores ( 0.6 or $0.8 \mathrm{~mm}$ i.d.). (c) Water cooled reaction chamber $(96 \mathrm{~mm}$ i.d., $500 \mathrm{~mm}$ length), nickel plated brass. $(d)$ Water cooled shell and tube heat exchanger; stainless steel tubes $11 \mathrm{~mm}$ i.d., $23 \mathrm{~mm}$ long. (e) Gas filtration chamber : polypropylene bag filters in parallel. $(f)$ Gas burner and suction system. $(g)$ On-line infrared gas analyzer (Perkin-Elmer mod. 457). Gas cell $6 \mathrm{~cm}$ long with $\mathrm{NaCl}$ windows. $(h)$ Cooling water flow rate and temperature rise measurements to evaluate the heat content of the plasma stream. The differential millivolt output signal from the Chromel-Constantan thermocouples is recorded on a strip chart (Kipp \& Zonen Micrograph BD5). (i) D. C. magnetic field generating circuit. (l) Argon hydrogen and boron trichloride cylinders : each gas is metered with a calibrated rotameter. The boron trichloride cylinder and feeding line are electrically heated at about $60^{\circ} \mathrm{C}$. Argon and hydrogen are S. I. O. grade with purities $>99.995 \%$ and $>99.99 \%$ respectively. Boron trichloride is F. L. U. K. A. grade with purity $>99 \%$.

ment. The plasma generator and the associated reaction chamber with the relevant control and measurement devices are described. Figure 2 shows the arc-plasma reactor and filters in operative assembly. Electrical power is supplied by AC-DC motorconverters (450 A max) of the arc welding type.

The main steps connected with the complex processes occurring in this apparatus consist of : (a) the thermo-chemical activation in the plasma generator of the hydrogen-argon mixture $\left(\left(\mathrm{H}_{2}\right) /(\mathrm{Ar})=3\right)$ that flows superimposed to the arc current ; $(b)$ the break-up of the plasma core and induced turbulence in the downward flowing plasma stream because of the interaction

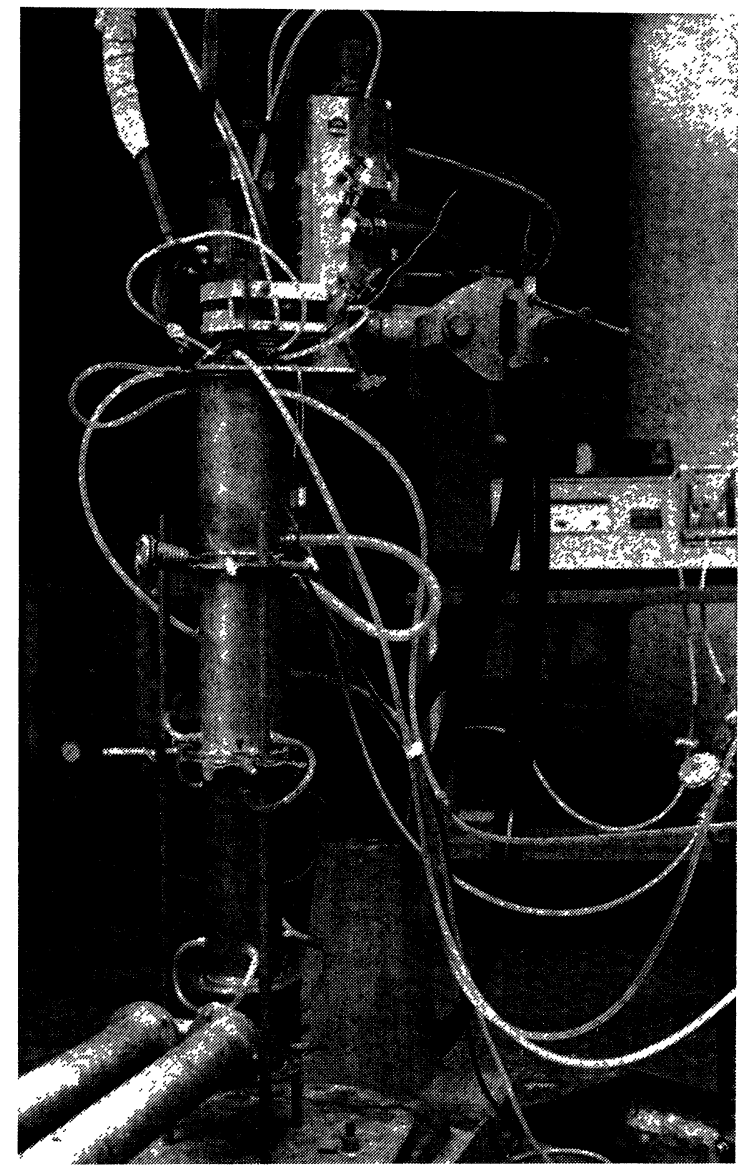

FIG. 2. - Arc plasma generator, reaction chamber and filters.

with the anodic magnetic field ; $(c)$ the radial injection and mixing of the gaseous $\mathrm{BCl}_{3}$ through the feeding segment downstream the anode. The chemical processes start and terminate in the high temperature turbulent jet which spreads into the reaction chamber.

The experimental runs are performed at $\mathrm{H}_{2}-\mathrm{Ar}$ flow rates in the range 40 to 901 (STP)/min. and a power input in the range of 8 to $15 \mathrm{~kW}$. The enthalpies of the jet are evaluated by the thermal balance on the cooling water of the reaction chamber when no reaction occurs. At lower power and higher flow rate a value of $3.5 \mathrm{~kJ} / 1$ (STP) is found, whereas at higher power and lower flow rate a value of $11.4 \mathrm{~kJ} / 1$ (STP) is measured. Thermodynamic temperatures $T_{\mathrm{t}}$ between $2700 \mathrm{~K}$ and $3750 \mathrm{~K}$ and an atomic dissociation degree of hydrogen between $3 \%$ and $50 \%$ is derived comparing the measured enthalpies with the thermodynamic data of ref. [5]. The $\left(\mathrm{H}_{2}\right) /\left(\mathrm{BCl}_{3}\right)$ molar ratio is in the range 3 to 20 with a maximum $\mathrm{BCl}_{3}$ flow rate of $0.445 \mathrm{~mol} / \mathrm{min}$.

More details of the operating procedure of this apparatus are reported in ref. [4].

Figure 3 shows the scheme of the equipment used in the glow discharge experiment. The pyrex discharge tube is similar to the well-known Geissler tube. The constricted portion is about $80 \mathrm{~mm}$ long with a $4 \mathrm{~mm}$ i. d. The stainless steel electrodes are cone shaped, 


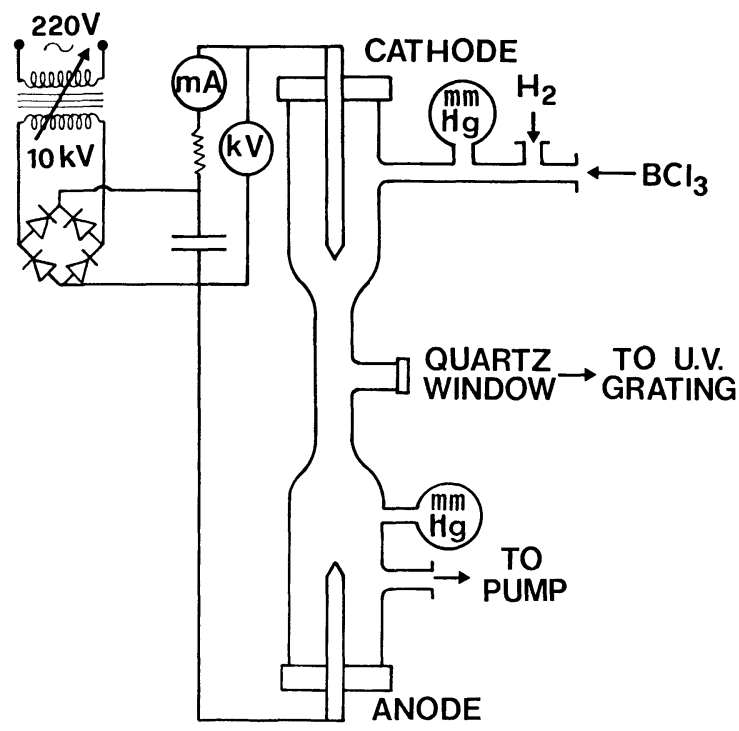

FIG. 3. - The glow-discharge experiment schematic.

$10 \mathrm{~mm}$ diameter and $160 \mathrm{~mm}$ apart. A premixed $\left(\mathrm{H}_{2}\right) /\left(\mathrm{BCl}_{3}\right)$ stream (molar ratio $\geqslant 2$ ), without $\mathrm{Ar}$, fed radially upstream the cathode, is activated by electron impact in the glow, passes the contricted portion of the tube towards the anode and is exhausted downstream. The flow rate is determined by measuring the pressure in the reactor and the volumetric vacuum pump suction rate. In the pressure range 3 to $10 \mathrm{mmHg}$ the flow rate is about $150 \mathrm{l} / \mathrm{min}$., giving a residence time of the reacting gases of some tenth of a millisecond. Absolute pressures are measured and $\left(\mathrm{H}_{2}\right) /\left(\mathrm{BCl}_{3}\right)$ ratio evaluated by means of a McLeod gauge. The power input is supplied by a bridge rectifier $(150 \mathrm{kV}, 50 \mathrm{~mA}$ max) driven by a variable high voltage transformer. An RC filter decreases the current ripple to $6 \%$ at $30 \mathrm{~mA}$. Input powers of $100 \mathrm{~W}$ with a current of $20 \mathrm{~mA}$ are typical operating values in the glow discharge experiments where the specific energy is similar to that required in the plasma process ( 3 to $10 \mathrm{~kJ} / 1$ (STP)), even operating with low power and flow rate.

3. Results. - In agreement with thermodynamic predictions [4] the infrared spectra of the discharge gases in the arc-plasma experiments show that even at the largest values of $\left(\mathrm{H}_{2}\right) /\left(\mathrm{BCl}_{3}\right)$ ratio, the only hydrogenated species present in appreciable quantities is dichloroborane $\mathrm{BHCl}_{2}$ with hydrogen chloride and unconverted boron trichloride.

Thus the overall reduction process may be regarded as two competitive reactions :

$$
\begin{gathered}
\frac{3}{2} \mathrm{H}_{2}+\mathrm{BCl}_{3} \rightleftarrows B_{\mathrm{s}}+3 \mathrm{HCl} ; \\
\Delta H_{298 \mathrm{~K}}=126 \mathrm{~kJ} / \mathrm{mol} \\
\mathrm{H}_{2}+\mathrm{BCl}_{3} \rightarrow \mathrm{BHCl}_{2}+\mathrm{HCl} ; \\
\Delta H_{298 \mathrm{~K}}=62.5 \mathrm{~kJ} / \mathrm{mol} .
\end{gathered}
$$

The experimental conversion extents $x_{1}$ and $x_{2}$ of $\mathrm{BCl}_{3}$ to $B_{\mathrm{s}}$ and $\mathrm{BHCl}_{2}$ respectively vs. the $\left(\mathrm{H}_{2}\right) /\left(\mathrm{BCl}_{3}\right)$ molar ratio are reported in figure 4 . The black circles refer to conversion values obtained by weighing the boron produced in those runs. The segments are obtained from the on-line quantitative infrared [4]

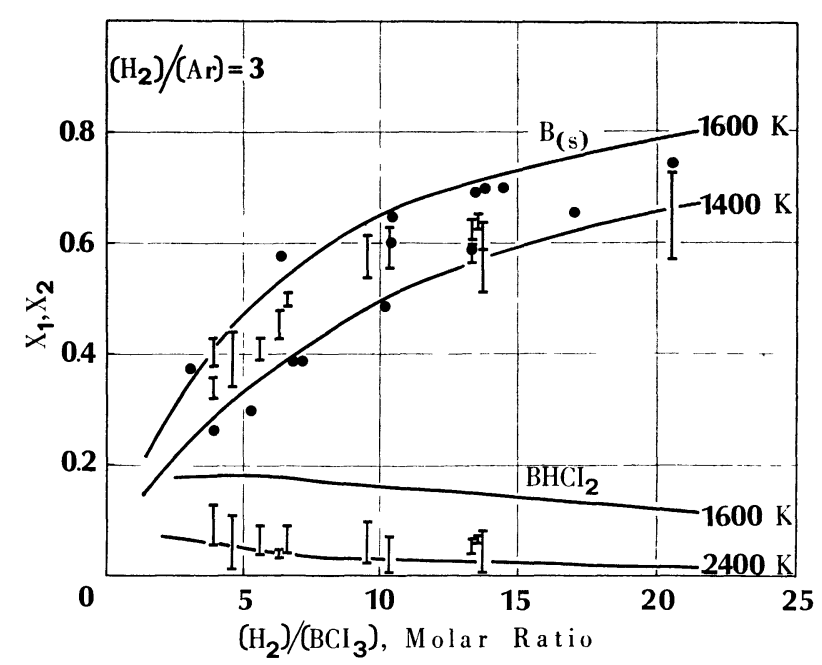

FIG. 4. - Conversion extents of $\mathrm{BCl}_{3}$ to $B_{\mathrm{s}}$ and to gaseous $\mathrm{BHCl}_{2}$ vs. $\left(\mathrm{H}_{2}\right) /\left(\mathrm{BCl}_{3}\right)$ molar ratio.

measurements of $\mathrm{BCl}_{3}, \mathrm{HCl}, \mathrm{BHCl}_{2}$ concentrations in the exhaust gases. According to the above hypothesis of parallel reduction processes, the conversion extents $x_{1}$ and $x_{2}$ are obtained from the following equations :

$$
\begin{aligned}
y_{\mathrm{BCl}_{3}} & =\frac{1-\left(x_{1}+x_{2}\right)}{1+0.5 x_{1}+\left(\mathrm{H}_{2}\right) /\left(\mathrm{BCl}_{3}\right) \cdot\left[1+(\mathrm{Ar}) /\left(\mathrm{H}_{2}\right)\right]} \\
y_{\mathrm{HCl}} & =\frac{3 x_{1}+x_{2}}{1+0.5 x_{1}+\left(\mathrm{H}_{2}\right) /\left(\mathrm{BCl}_{3}\right) \cdot\left[1+(\mathrm{Ar}) /\left(\mathrm{H}_{2}\right)\right]} \\
y_{\mathrm{BHCl}_{2}} & =\frac{x_{2}}{1+0.5 x_{1}+\left(\mathrm{H}_{2}\right) /\left(\mathrm{BCl}_{3}\right) \cdot\left[1+(\mathrm{Ar}) /\left(\mathrm{H}_{2}\right)\right]}
\end{aligned}
$$

where $y_{\mathrm{BCl}_{3}}, y_{\mathrm{HCl},}, y_{\mathrm{BHCl}_{2}}$ represent the measured molar fractions. In figure 4, $x_{1}$ measurements exhibit a satisfactory agreement where a nearly constant $x_{2}$ value of about $10 \%$ appears. Conversion values $x_{1}$ between $30 \%$ and $70 \%$ are measured in correspondence with the lower and the upper limits of the $\left(\mathrm{H}_{2}\right) /\left(\mathrm{BCl}_{3}\right)$ ratios investigated. Moreover conversion data are nearly independent of the power input and the reactant flow rate and only depend on the $\left(\mathrm{H}_{2}\right) /\left(\mathrm{BCl}_{3}\right)$ ratio. The conversion data evaluated by the heterogeneous equilibrium calculations for boron at $1400 \mathrm{~K}$ and $1600 \mathrm{~K}$ and $\mathrm{BHCl}_{2}$ at $1600 \mathrm{~K}$ and $2400 \mathrm{~K}$ are plotted as the isotherms of figure 4 . The actual conversion to solid boron appears to agree approximately with a frozen thermodynamic condition in the range 1400 to $1600 \mathrm{~K}$. From such results it seems reasonable to infer that solid boron is present because the inverse heterogeneous reactions (1) between $\mathrm{HCl}$ and $B_{\mathrm{s}}$ is kinetically limited and frozen in the above mentioned temperature range. The results of figure 4 suggest that mixing and homogeneous reactions of $\mathrm{BCl}_{3}$ are very 
fast processes. The photographs of the reduction flame show that the emission of white continous radiation from the nuclei of the solid boron particles at high temperature start without appreciable delay after the input of the $\mathrm{BCl}_{3}$ reactant. The previous suggestion thus seems confirmed. The boron is produced as an extremely fine powder ; its colour varies between dark and yellow brown. The purity reaches about $99 \%$ (by weight). Semiquantitative analyses show that the most important contaminants are copper, silicon, iron and oxygen.

Figure 5 presents an electron microscope photograph of the product at about $51500 x$. In addition to

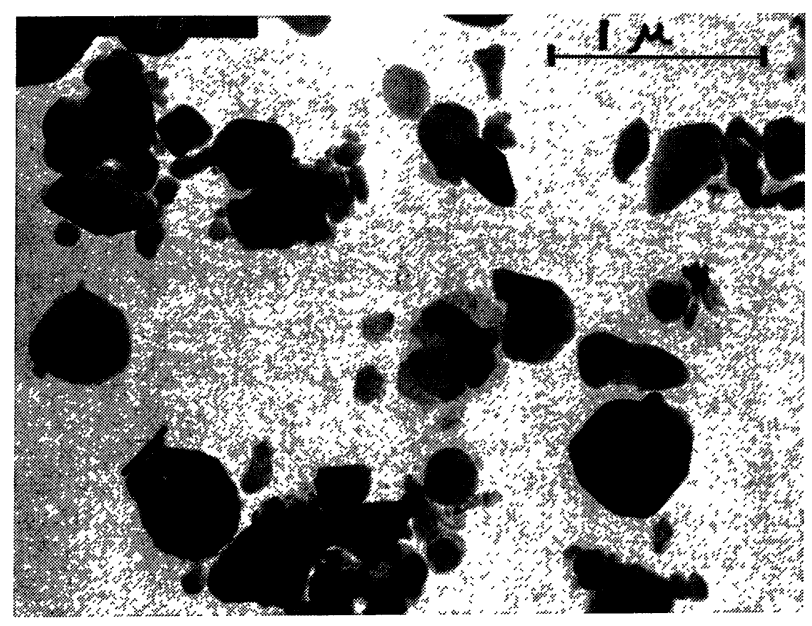

FIG. 5. - Electron microscope photograph of some boron particles.

product fineness, the crystalline shape of some particles is quite evident. The thinness of some platelet-shaped particles is apparent, as suggested by their transparence when occasional superimposition occurs. Rhomboedric and tetragonal diffraction patterns have been observed by X-ray analysis. In figure 6 a typical granulometric distribution curve obtained by electron microscopy is presented. The curve is rather narrow $(0.05$ to $0.15 \mu \mathrm{m})$. Its characteristic shape is similar in any experimental condition, the particle size and the curve spreading increase whenever the initial reaction temperature and the residence time of the growing nucleus in the reduction flame increase.

A quite different phenomenology of $\mathrm{BCl}_{3}$ reactions with hydrogen appears in the glow discharge. This results in boron nucleation and growth in heterogeneous phase on both the discharge tube walls and cathode surfaces. The wall deposit appears uniform, compact and dark brown. Experiments prove that the wall deposit occurs both when the $\mathrm{H}_{2}-\mathrm{BCl}_{3}$ reactants are premixed and when the single reagents are separately fed to the constricted portion of the tube. In the latter case the contact of the reagents with the cathodic surface is avoided. The wall deposit can be supposed to derive from the gaseous boron diffusion and reduction reactions occurring in the discharge. So far as the

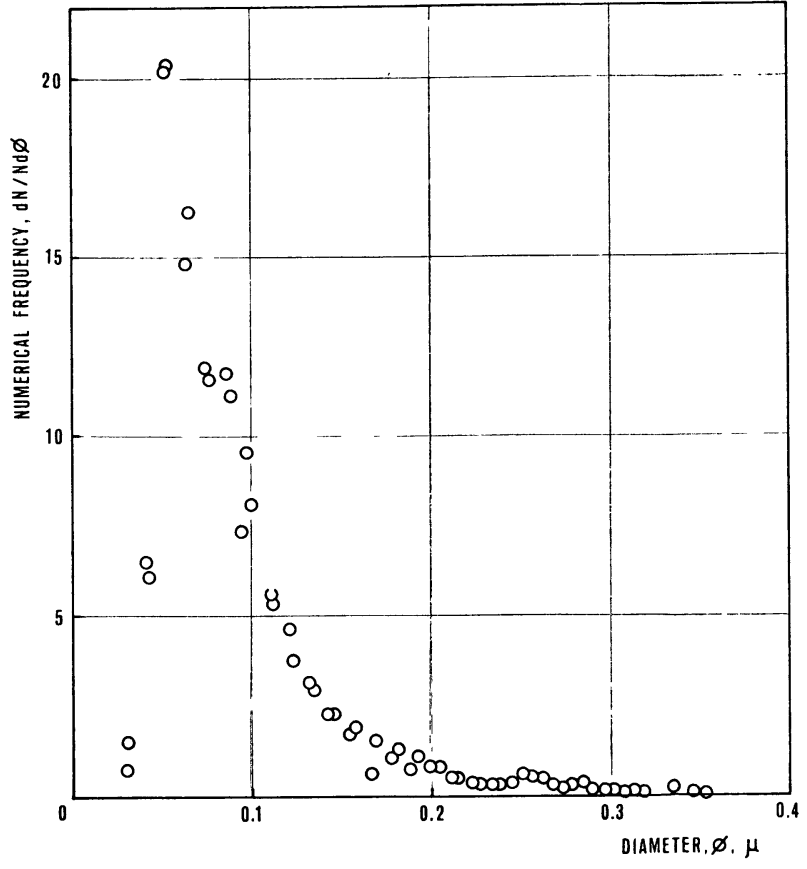

Fig. 6. - Typical size distribution curve of boron particles.

deposit growing on the cathode is concerned this could be due to a surface thermal reaction mechanism.

There are no data for the gaseous product of the reduction reactions in the glow discharge.

The results obtained, both for the thermally activated and the electron impact activated processes, are insufficient to allow any hypothesis regarding the reaction mechanism.

Data relating to the presence of atomic and molecular radical species are obtained by spectroscopic investigations in the visible and near U. V. range. The spectrograph is a grating quartz optics Steinheil Mod. G. H. with a reciprocal dispersion of about $1.5 \AA / \mathrm{mm}$ at the exit slit. Spectra intensity is detected by means of a U. V. photomultiplier and recorded on a strip chart recorder.

Because of the high electron temperatures involved, electron transition spectra of $H$ (Balmer), $B(2497 \AA$ doublet), $\mathrm{H}_{2}$ (many-lines), $\mathrm{BCl}\left({ }^{1} \Pi \rightarrow^{1} \sum, 2660\right.$ to $2848 \AA), B H\left({ }^{1} \prod \rightarrow^{1} \sum, 4331 \AA\right)$ are always present in the discharge tube [6], [7], [8]. The vibrational structure is evident in the last two molecular spectra but the rotational spectrum is easily resolved only in the $B H$ case. Unresolved broad bands of polyatomic type at 5430,5 560, 5 690, $5320,5000 \AA$, the first very intense, appear also at the lower pressures. Their sensitivity to the $\mathrm{BCl}_{3}$ partial pressure suggests their attribution to the excitation of this molecule. No continous emission appears.

$B$ and $H$ spectra are present also in the plasma reduction flame at atmospheric pressure, but only at maximum power input and in the higher temperature reaction zone. They are not detected downstream the $\mathrm{BCl}_{3}$ feeder. $\mathrm{BCl}$ and polyatomic species spectra are 
also absent. This is in agreement with the predicted low electron temperature for the reduction flame. However there is an intense continuum due to the emission by solid particles at high temperatures. The ${ }^{1} \prod \rightarrow{ }^{1} \sum B H$ transition is always intense, compared with the continuum, even at a considerable distance from the $\mathrm{BCl}_{3}$ distributor. This could mean that the $B H$ molecule excited at the upper electronic level ${ }^{1} \Pi$ is an intermediate in a complex series of chemical reactions occurring in the recombination-reduction flame.

The rotational structure of the vibrational transitions $(0,0)$ at $4331 \AA$ and $(1,1)$ at $4367 \AA$ of the ${ }^{1} \prod \rightarrow^{1} \sum$ $B H$ electronic transition can be observed in figure 7 . Particularly the intense R-branch lines of the $(0,0)$ transition do not overlap with other lines. Such a favourable situation allowed the relative intensity of the first twenty lines of the R-branch to be measured unambiguously as detected by the photoelectric record of the spectrum.

Rotational temperatures $T_{\mathrm{r}}$ of the hottest area of the reduction flame near the $\mathrm{BCl}_{3}$ feeder are evaluated $\left({ }^{1}\right)$. $T_{\mathrm{r}}$ measurements are affected by a substantial indetermination due both to the non linear contribution to the line intensity by the point sources of the flame at different temperatures and to the random time fluctuations of the line intensity because of the jet turbulence. Since the scanning times of the spectra are relatively long ( $\sim 4 \mathrm{~min}$.), the low frequency flame fluctuations seem to be the main contribution to the data scattering of the line intensity. As a consequence, accuracy of $\pm 100 \mathrm{~K}$ is estimated for the $T_{\mathrm{r}}$ measurements. $T_{\mathrm{r}}$ data are reported in table $I$ at three operating conditions of the plasma reactor together with the $T_{\mathrm{t}}$ data evaluated by the thermal balance of the reaction chamber as previously mentioned. An uncertainty in $T_{t}$ values not exceeding $50 \mathrm{~K}$ is estimated from the uncertainties of the measured plasma enthalpies as reported in the table. These last ones are mainly caused by errors in measuring the cooling water flow rate.

Such measurements appear reliable and sensitive despite the above mentioned difficulties and the not obvious physical assumptions. In fact comparing the table data proves that $T_{\mathrm{t}}$ represents a superior limit for the temperature $T_{\mathrm{r}}$ of the reduction flame which represents the reaction temperature since its endothermicity. Moreover, since a high atomic dissociation degree supplies recombination energy to the system, the difference between $T_{\mathrm{t}}$ and $T_{\mathrm{r}}$ is considerable for a low dissociation degree, i. e. for a low power input and/or a high $\left(\mathrm{H}_{2}\right) /\left(\mathrm{BCl}_{3}\right)$ molar ratio. Further agreement with the above expectation is demonstrated by the

(1) In fact, for the R-branch lines $\left(J^{\prime}-J^{\prime \prime}=+1\right)$, the intensity of the $1 \Pi \rightarrow 1 \Sigma(0,0)$ transition is $[9]$ :

$$
I\left(J^{\prime}, T\right) \propto\left(J^{\prime}+1\right) . \exp \left[-\frac{B^{\prime} J^{\prime}\left(J^{\prime}+1\right) h c}{k T}\right]
$$

where : $J^{\prime}, J^{\prime \prime}$ are the rotational quantum numbers of the upper and the lower state respectively ; $B^{\prime}=11.90 \mathrm{~cm}^{-1}[10]$ is the upper state rotational constant, corrected for vibration anharmonicity; $h, k$ the Planck and Boltzmann constants and $\mathrm{c}$ the light velocity. The temperature $T$ is easily obtained from the angular coefficient of the straight line by interpolating the points of the diagram $\ln \frac{I\left(J^{\prime}, T\right)}{J^{\prime}+1}$ vs. $J^{\prime}\left(J^{\prime}+1\right)$ where $I\left(J^{\prime}, T\right)$ is the measured line intensity corresponding to the rotational quantum number $J^{\prime}$.

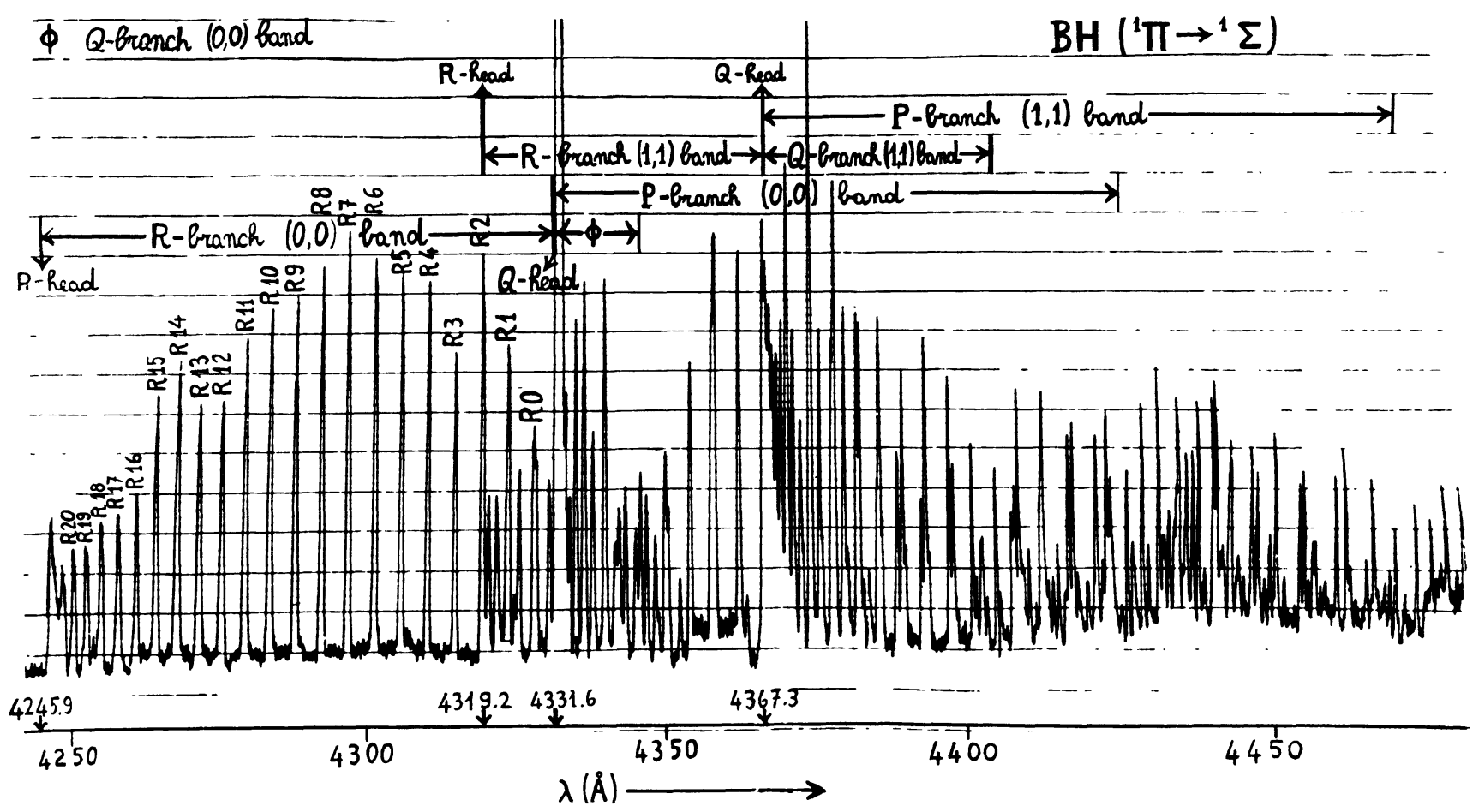

FIg. 7. - Photoelectric record of the $B H 1 \Pi \rightarrow 1 \Sigma$ electronic transition intensity. 
greater difference between $T_{\mathrm{t}}$ and $T_{\mathrm{r}}$ corresponding to a lower enthalpy content of the jet; if the last is constant, a measurable decrease of $T_{\mathrm{r}}$ is observed whenever the flow rate of $\mathrm{BCl}_{3}$ increases.
The Authors are indebted to the electron microscopy group of the Research Institute "G. Donegani », Novara (Italy), of the Montedison Co., for providing the analysis of the boron samples.

\section{References}

[1] Biggerstaff, G. E., Gollinher, W. R., Harris, R. L., Rossmassler, W. R., AEC Report. US At. Energy Comm., KY-453 (1964).

[2] MarkovskiI, L. Ya., Lvova, V. I., Kondrashev, Y. D., Bor. Ir. Konf. po Khim. Borai Ego Svedin 36 (1958).

[3] Hamblyn, S. M. L., Reuben, B. G., Thompson, R., Commun. to the Sympos. on Special Ceramics at BCRA (1970).

[4] Diana, M., Russo, G., De Marino, L., Chim. Ind. 56 (1974) 544.

[5] Capitelli, M., Ficocelli, E., Molinari, E., «Equilibrium Composition and Thermodynamic Properties of Mixed Plasmas" ; (Ist Chim. Gener.-Università di Bari, Italy) 1972.
[6] Pearse, R. W. B., Gaydon, A. G., The Identification of Molecular Spectra (Chapman and Hall Ltd, London) 1965.

[7] Suchard, S. N., Spectroscopic Data (IFI Plenum, New York) 1975, vol. 1.

[8] Rosen, B., Données Spectroscopiques Relatives aux Molécules Diatomiques (Pergamon Press, Oxford) 1970.

[9] Herzberg, G., "Molecular Spectra and Molecular Structure » Vol. 1 (D. Van Nostrand Co., New York) 1950, 127, 208.

[10] Johns, A. W. C., Grimm, F. A., Porter, R. F., J. Mol. Spectros. 22 (1967) 435. 